\title{
Consultants or Trainees: Whose patient's do better following surgical coronary revascularisation?
}

\author{
Damian Balmforth", Daniel Jones, Sean Gallagher, Andrew Wragg, Alex Shipolini, Kit Wong, Rakesh Uppal \\ From World Society of Cardiothoracic Surgeons 25th Anniversary Congress, Edinburgh \\ Edinburgh, UK. 19-22 September 2015
}

\section{Background/Introduction}

It is a commonly held belief that patients undergoing coronary artery bypass grafting (CABG) have better outcomes when their surgery is performed by a consultant rather than a surgical trainee. However, there are few studies that analyse the relationship between operator grade and clinical outcomes.

\section{Aims/Objectives}

To investigate the effect of operator grade on the outcomes of CABG in the setting of a major tertiary centre with a nationally accredited cardiac surgical training programme.

\section{Method}

A retrospective observational cohort study was performed on prospectively collected data for all patients undergoing CABG between January 2003 and July 2011.

\section{Results}

A total of 6689 patients underwent CABG of which trainees performed 1968 (29.4\%). The proportion of procedures performed by trainees declined over time from $30.2 \%$ in 2003 to $26 \%$ in 2010 . Consultants tended to perform more high risk operations with their patients being more likely to have high Euroscores, be urgent cases, and have cardiogenic shock. In the unadjusted Cox analysis, consultant operator grade was associated with an increase in 5 year mortality [HR: 1.26 (95\% CI: 1.07-1.47)]. However, this association did not persist following multiple adjustment for co-morbidities [HR: 1.02 (95\% CI: 0.87-1.20)]. In a propensity score analysis that stratified patients by risk, whilst consultants were found to have performed a greater proportion of high risk cases, there was no significant difference seen in 5 year

Barts Heart Centre, St Bartholomew's Hospital, London, EC1A7BE, UK mortality between consultants and trainees across the range (RR 1.04 (95\% CI: 0.86-1.24)].

\section{Discussion/Conclusion}

There is no difference in clinical outcomes between trainees and consultants where CABG is performed in a centre with a dedicated training programme under direct consultant supervision.

Published: 16 December 2015

doi:10.1186/1749-8090-10-S1-A348

Cite this article as: Balmforth et al:: Consultants or Trainees: Whose patient's do better following surgical coronary revascularisation? Journal of Cardiothoracic Surgery 2015 10(Suppl 1):A348.

Submit your next manuscript to BioMed Central and take full advantage of:

- Convenient online submission

- Thorough peer review

- No space constraints or color figure charges

- Immediate publication on acceptance

- Inclusion in PubMed, CAS, Scopus and Google Scholar

- Research which is freely available for redistribution 